\title{
Children's trips to school dominated by unhealthy food advertising in Sydney, Australia
}

\author{
Korina J Richmonda,d, Wendy L Watson ${ }^{\mathrm{b}}$, Clare Hughes ${ }^{\mathrm{b}}$ and \\ Bridget Kelly \\ a Cancer Prevention and Advocacy, Cancer Council NSW, Sydney, Australia \\ ${ }^{b}$ Cancer Programs Division, Cancer Council NSW, Sydney, Australia \\ c Early Start, School of Health and Society, University of Wollongong, NSW, Australia \\ ${ }^{d}$ Corresponding author: korina.richmond@nswcc.org.au
}

\section{Article history}

Publication date: March 2020

Citation: Richmond KJ, Watson WL, Hughes C, Kelly B. Children's trips to school dominated by unhealthy food advertising in Sydney, Australia. Public Health Res Pract. 2020;30(1):e3012005. https://doi.org/10.17061/phrp3012005

\section{Introduction}

Children's exposure to unhealthy food advertising contributes to childhood obesity by influencing food preferences and purchase requests, leading to poor dietary intake. ${ }^{1}$ For an individual, exposure to advertising on the school commute is largely unavoidable, unlike other advertising forms such as television, where exposure can be reduced by limiting screen time. Advertising on public transport infrastructure is under New South Wales (NSW) state government control and should align with broader policy priorities to reduce childhood obesity, including creating environments that support healthy eating. ${ }^{2}$ Previous Australian research has focused on food marketing in the immediate area surrounding schools ${ }^{3}$ and train stations. ${ }^{4}$ This study aimed to examine the number and type of food advertisements to which children are exposed when using public transport or walking to school in Sydney, Australia.

\section{Methods}

A convenience sample of 21 schools (representing 23000 students) was selected from the 50 largest primary and secondary government schools within the Greater Sydney City Statistical Area Level 4. The sample included high and mid/low decile socio-economic areas and various geographic locations: inner Sydney (<12 km from Central Station) and outer Sydney (>12 km from Central Station).

Theoretical train, bus and walking routes were planned for a one-way trip to each school using Google maps. Train routes included two train stations, one nearest the school and a further one stop away, the train trip and walk/ bus to the school gate. Bus trips included waiting at a bus stop, travelling 2-3 km, alighting at the stop closest to the school and walking to the gate. The walking route was a $600 \mathrm{~m}$ walk along a main road to the school gate. This distance was reported by the Longitudinal Study of Australian Children ${ }^{5}$ as the average distance walked by children who usually walked to school. Researchers travelled the routes and noted all visible advertisements. 
Advertisements greater than A4 size that appeared in outdoor spaces - in train stations (vending and billboards), and on buses, bus shelters and telephone posts - were included, except those on shop fronts and sandwich boards. Advertised foods were categorised as either 'core' (foods recommended to meet daily nutrient requirements), 'discretionary' (foods that are surplus to daily nutrient requirements) or 'miscellaneous' (tea, coffee, supplements, meal delivery apps) using criteria adapted from previous research. ${ }^{3}$ If the advertisement had multiple products, the foremost/largest product was used to determine the food product category.

Data collection and coding was carried out by two researchers in May/June 2018. Descriptive statistics were used to assess the total number, proportion and rate of advertisements on routes to school. One-way ANOVA was used to compare differences in the mean rate of advertisements by travel mode. Independent t-tests were used to compare the frequency of advertisements by school type, socio-economic group and location.

\section{Results}

A total of 762 advertisements were observed across the 53 school routes sampled. Advertisements on NSW State Government-owned infrastructure (such as on buses and at train stations) made up $97.4 \%$ of all advertisements observed.

Almost one-third (32\%) of advertisements were for foods or beverages and of those, $75 \%$ promoted discretionary products. Core food and miscellaneous advertisements contributed to $11 \%$ and $14 \%$ of total food and beverage advertisements, respectively. Fast foods such as burgers, chips and pizza were the most frequently advertised food and beverage products (23\%), followed by sugary drinks (17\%) and snack foods (16\%). Alcohol advertisements contributed $6 \%$ of all food and beverage advertisements.

On average, there were significantly more advertisements per trip for discretionary foods on train routes compared with bus and walking routes (Table 1). Across all transport routes, trips within inner Sydney had significantly higher rates of discretionary food advertisements than trips in outer Sydney (4.8 vs. 2.1, $p=0.002$ ), although the proportion of discretionary food advertisements was similar $(73 \%$ and $81 \%$ of total food advertisements, respectively). There were no significant differences in the rate of discretionary and core food advertisements per trip between primary and secondary schools, or across schools in high and $\mathrm{mid} / \mathrm{low}$ decile socioeconomic areas.
Table 1. Average rate of advertisements per trip (n)

\begin{tabular}{lccc}
\hline $\begin{array}{l}\text { Advertisement } \\
\text { category }\end{array}$ & Train (13) & Bus (20) & Walk (20) \\
\hline Total & $24.5^{\mathrm{a}}$ & $14.5^{\mathrm{b}}$ & 7.7 \\
\hline Food and beverage & $9.6^{\mathrm{a}, \mathrm{c}}$ & 3.7 & 2.3 \\
\hline $\begin{array}{l}\text { Discretionary food } \\
\text { and beverage }\end{array}$ & $7.3^{\mathrm{a}, \mathrm{c}}$ & 2.7 & 1.7 \\
\hline $\begin{array}{l}\text { Core food and } \\
\text { beverage }\end{array}$ & $1.4^{\mathrm{a}, \mathrm{d}}$ & 0.4 & 0.1 \\
\hline
\end{tabular}

\footnotetext{
a Significantly more when compared with walking $(p<0.02)$

Significantly more when compared with walking $(p<0.05)$

Significantly more when compared with taking the bus $(p<0.02)$

d Significantly more when compared with taking the bus $(p<0.05)$.
}

\section{Discussion}

This study estimates that depending on transport mode, children living in the Greater Sydney area were exposed to between 1.7 and 7.3 discretionary food advertisements per trip to school in May/June 2018. Therefore, travelling to and from school for one year, children would be exposed to more than 2800 discretionary food advertisements if travelling on trains and 1000 discretionary food advertisements if travelling on buses.

Three-quarters of food and beverage advertisements related to discretionary foods. Only 11\% promoted core food products. These results are similar to previous research that found $80 \%$ of food advertising at Sydney train stations was for discretionary products whereas only $8 \%$ promoted core products. $^{4}$

School routes within inner Sydney had more than double the rate of all advertising compared with outer Sydney, with significant differences also found across all advertising categories including discretionary food and drink advertising. This was expected as population density is higher in inner Sydney, and thus, that area is likely to be more attractive to advertisers due to its higher potential reach. Comparable trends were found previously in research investigating food advertising around primary schools in Australia. ${ }^{3}$

Food marketing influences children's diets ${ }^{1}$, and this is likely to be true for outdoor advertising. ${ }^{6}$ Repeated exposure to unhealthy food advertising on school trips, especially coupled with exposure to other forms of advertising such as on television and online, means children are immersed in an obesogenic environment that undermines efforts to develop healthy eating habits. ${ }^{1}$

State governments have the ability to restrict or ban unhealthy food advertising from state-owned property such as trains and buses to help reduce exposure to unhealthy advertisements. In 2015, the Australian Capital Territory Government banned discretionary food advertising on its buses. ${ }^{7}$ In April 2019, the Queensland 
Government announced that unhealthy marketing would be phased out of outdoor advertising spaces, including bus stops, train stations and road corridors. ${ }^{8}$ These actions complement other strategies to reduce childhood obesity statistics.

\section{Conclusion}

NSW and other state and territory governments have an opportunity to reduce children's exposure to unhealthy food advertising by banning advertising of discretionary foods on public transport infrastructure. This action would demonstrate a commitment to creating environments that help children to develop healthy eating habits and would support other government initiatives to reduce childhood obesity.

\section{Acknowledgements}

We acknowledge Fran Martino for contributing to the design and data collection in this project. This work was supported by the Australian Research Council (ARC Linkage Project: LP140100120).

\section{Peer review and provenance}

Externally peer reviewed, not commissioned.

\section{Competing interests}

None declared.

\section{Author contributions}

KR was responsible for the design, implementation, drafting, analysis of data, and editing of the manuscript. WW, $\mathrm{CH}$ and $\mathrm{BK}$ were responsible for designing, reviewing and editing the manuscript.

\section{References}

1. Cairns G, Angus K, Hastings G, Caraher M. Systematic reviews of the evidence on the nature, extent and effects of food marketing to children. A retrospective summary. Appetite. 2013;62:209-15.

2. NSW Government Centre for Population Health. Premier's priority: reduce overweight and obesity rates of children by 5\% over 10 years. Sydney: NSW Government; 2016 [cited 2019 Apr 16]. Available from: www.health.nsw.gov. au/heal/Publications/Premiers-priority-childhood-obesitydelivery-plan.pdf

3. Kelly B, Cretikos M, Rogers K, King L. The commercial food landscape: outdoor food advertising around primary schools in Australia. Aust N Z J Public Health. 2018;32:522-8.

4. Sainsbury E, Colagiuri S, Magnusson R. An audit of food and beverage advertising on the Sydney metropolitan train network: regulation and policy implications. BMC Public Health. 2017; 17(1):490.

5. Australian Government Department of Families, Housing, Community Services and Indigenous Affairs. Growing up in Australia: the Longitudinal Study of Australian Children: 2009-10 annual report. Canberra: Australian Government; 2011 [cited 2019 Sep 6]. Available from: www.dss.gov.au/sites/default/files/documents/lsac_ ar_200910.pdf

6. Scully M, Wakefield M, Niven P, Chapman K, Crawford D, Pratt IS, et al, for the NaSSDA Study Team. Association between food marketing exposure and adolescents' food choices and eating behaviours. Appetite. 2012;58(1):1-5.

7. ACT Government. Buses will no longer advertise junk food, alcohol, gambling and weapons. Canberra: ACT Government; 2015 [cited 2020 Feb 12]. Available from: www.cmtedd.act.gov.au/open_government/inform/ act_government_media_releases/rattenbury/2015/buseswill-no-longer-advertise-junk-food,-alcohol,-gamblingand-weapons

8. ABC News. Junk food ads binned by Queensland Government in bid to address obesity. Sydney: ABC; 2019 [cited 2020 Feb 12]. Available from: www.abc.net. au/news/2019-04-21/junk-food-ads-binned-queenslandgovernment-crackdown/11034284

\section{Copyright: (c)}

(c) 2020 Richmond et al. This article is licensed under the Creative Commons Attribution-NonCommercial-ShareAlike 4.0 International Licence, which allows others to redistribute, adapt and share this work non-commercially provided they attribute the work and any adapted version of it is distributed under the same Creative Commons licence terms. See: www.creativecommons.org/licenses/by-nc-sa/4.0/ 